\title{
Two are Better than One: A Collaborative Professional Development Model
}

\author{
Marlene Zakierski, Alice Siegel \\ The Sage Colleges, Albany, New York, United States of America
}

\begin{abstract}
The authors of this paper were the lead team that initiated this Literacy/Technology project, entitled SPLASH (Sharing Practices that Lead to Academically Successful Habits). The dissemination project included a charter school, grades PreK-8 and two other schools in Westchester County, New York: one K-8 school and one middle school. The overarching goal of the dissemination project was to provide effective and meaningful staff training with an emphasis on English Language Arts (ELA) strategies and data analysis to improve student performance and raise New York State ELA test scores in schools in need of improvement in a climate of true collaboration. . The results of this project indicate that a successful professional development program is dependent upon the collaboration of peer teachers while learning new skills that is nurtured and monitored by on-going coaching. It is imperative that it is led by skilled and dedicated literacy practitioners with both current research knowledge and practical classroom experience. Furthermore, a strong background in administration is required to facilitate leadership in creating these productive professional learning communities.
\end{abstract}

\section{Introduction}

Research describes many professional development programs that support teachers implementing the new Common Core State Standards. It is generally accepted that the pace of change will be faster than previously experienced for many teachers and the stakes will be higher [6].

All teachers will require time to gain the knowledge and skills to apply the new tools in real work settings, and the success of such efforts will be accelerated when work is conducted in collaboration with peers. DuFour [7] has pointed out that in order to create high quality professional learning communities the professional development must focus on an agreement on what students must learn and at what pace; common grade level interim assessments; team data analysis of academic interventions; sharing and supporting fellow colleagues to achieve best teaching practices that will produce a systematic way of intervention. "Building shared knowledge, learning together, is essential to every step of the PLC (professional learning community) journey... If you just put teachers together in a room and tell them to collaborate, there's no evidence that that's going to improve student achievement at all" (Thiers, 2016).

With that in mind the authors applied and received a Charter School Dissemination Grant in New York State. The goal of the dissemination project was to provide effective and meaningful staff training aligned to Common Core Standards with an emphasis on ELA strategies, data analysis to improve student performance as well as raise NYS ELA test scores in schools in need of improvement. Dissemination activities focused on professional development to help teachers at the three schools learn how to use data to inform their instructional practices. Some of these activities are:

- Learn to structure team/grade meetings that focus on student progress through the use of data

- Become reflective in teaching approaches/ practices (examining what worked/did not work)

- Learn how to articulate and collaborate effectively as part of a professional team

- Use data effectively to inform instruction (analyze data to determine student needs, chart student progress, make thoughtful programming decisions (Intervention vs. enrichment)

- Target measureable instructional outcomes with specific student needs in mind

- Set up and organize an effective, supportive literacy environment for teaching and learning

- Learn how to make students more accountable for their own learning.

The dissemination project provided workshops to educators at partner schools in effective instructional practices. This training prepared educators to implement research based literacy practices aligned to New York State Common Core Standards.

\section{Common Core Learning Standards Addressed}

The proposed initiative is aligned with the spirit of the Common Core. Specifically, it helps educators address the following standards in grades 4-5 and 78:

CCR.R.2. Determine central ideas or themes of a text and analyze their development; summarize the key supporting details and ideas. 
Skills addressed: Main idea, summarize, facts v. opinion, determining importance, central ideas [6].

CCR.R.4. Interpret words and phrases as they are used in a text, including determining technical, connotative, and figurative meanings, and analyze how specific word choices shape meaning or tone.

Skills addressed: Determining meaning, word choice, questioning, analyzing craft [6].

CCR.R.7. Integrate and evaluate content presented in diverse media and formats, including visually and quantitatively, as well as in words.

Skills addressed: Evaluative understanding, inference, connections, visualizing, compare v. contrast, deepening meaning, interpretations, drawing conclusions [6].

The lead team for this project was the authors of this paper. The paper provides a description of this successful three-year professional development program entitled SPLASH (Sharing Practices that Lead to Academically Successful Habits). During the paper presentation, the authors/presenters will share the successful outcomes of this professional development model with actual literacy lessons and data analysis strategies presented by the grant participating teachers. This will be demonstrated by the various different technologies that were implemented during the project. It is hoped that other school districts that are looking to improve student achievement will replicate this effective professional development model.

\section{Demonstrated Need or Demand}

The Charter School partnered with two public schools in Westchester County, New York.

Following are data that demonstrated the need for more effective English Language Arts instruction at the two public schools.

One of the public schools, a K-8 school was designated a Restructuring Comprehensive

School on the 2010-2011 New York State Report

Card. Only $42 \%$ of fourth grade students passed the ELA test in 2010-2011. The principal expressed a desire to focus the dissemination

Table 1. Comparing Percentage Students in Grades 4-6 scoring at Levels 3 and 4 on the NYS ELA Test at the Charter School and K-8 public school and New York State in 2011-2012

\begin{tabular}{|c|c|c|c|}
\hline \multicolumn{4}{|c|}{ Passing Rates on ELA for SY 2011-2012 } \\
\hline Grades & $\begin{array}{l}\text { Charter } \\
\text { School }\end{array}$ & $\begin{array}{l}\text { K-8 } \\
\text { Public } \\
\text { School }\end{array}$ & $\begin{array}{l}\text { NYS } \\
\text { Average }\end{array}$ \\
\hline 4 & $83 \%$ & $42 \%$ & $56 \%$ \\
\hline 5 & $84 \%$ & $41 \%$ & $53 \%$ \\
\hline 6 & $97 \%$ & $42 \%$ & $56 \%$ \\
\hline
\end{tabular}

Table 1 above shows students enrolled at the K-8 public school scoring $12 \%$ below the state average for students in grade 5 and $14 \%$ below in grade 6 . It should be noted that the overall passing rates of students in 4th grade in the district-wide for 20102011 was $42 \%$, which shows that $14 \%$ of the students performed below the state average.

Further noted on the NYS Report Card, this school did not meet accountability group performance targets for elementary and middle school students identified as Black/African American, Hispanic, LEP/ELLs and economically disadvantaged students in ELA. The low performance of students across all grade levels and groups demonstrated a need for this proposed dissemination partnership with the Charter School. Targeting grades 4 and 5 specifically for this program was a decision made by the school principal who expressed that teachers at these grade levels in his school would be the most receptive to the program. Additionally, he felt improving performance of students at these grade levels would positively impact the NYS ELA assessments as students' transition from elementary to middle school.

\section{Public Middle School X}

Public Middle School X was designated a focus school in need of improvement for not making AYP in English Language Arts and not meeting accountability measures for students with disabilities and students who are economically disadvantaged. Review of the 2010-2011 NYS Report Card showed the school needed to increase reading proficiency levels for seventh and eighth grade students.

Table 2. Percentage of Students in Grades 7 and 8 Scoring at Level 3 and 4 on the NYS ELA

\begin{tabular}{|c|c|c|c|}
\hline \begin{tabular}{|c|c|} 
Public \\
School X Grade 7
\end{tabular} & \multicolumn{2}{|c|}{$\begin{array}{l}\text { Mublic Middle School } \\
\text { X Grade 8 }\end{array}$} \\
\hline $\begin{array}{l}2010- \\
2011\end{array}$ & $39 \%$ & $\begin{array}{l}2010- \\
2011\end{array}$ & $47 \%$ \\
\hline $\begin{array}{l}2009- \\
2010\end{array}$ & $43 \%$ & $\begin{array}{l}2009- \\
2010\end{array}$ & $58 \%$ \\
\hline
\end{tabular}

Table 2 above represents NYS ELA proficiency levels of seventh and eighth grade students in the Public Middle School X in 2009-2010 and 20102011. In 2011, more than half of the students in both grades did not meet standards. That same year seventh graders scored below the state average (state average $48 \%$ vs. Public Middle School X 39\%) and both grades dropped in test scores from one year to the next. This data indicates a need for professional development to remediate the low reading performance of students in a school that is reported to have good attendance rates (96\%-98\%), low 
suspension rates $(3 \%-11 \%$ over three years), a student stability level of $97 \%$, and students performing better in other subject areas, i.e. grade 8 science tests.

\section{Second and following pages}

The project included a charter school that serves approximately 650 students in grades $\mathrm{K}-8$ who are approximately $85 \%$ minority and $87 \%$ qualified for free and reduced lunch. The public K-8 school also serves approximately 650 students and a little more than $76 \%$ of those students qualify for free or reduced lunch. The middle school, serving grades 7 and 8, serves approximately 250 students of which $26.3 \%$ qualified for free and reduced lunch. All three participating schools are located in Westchester County, New York and serve predominately minority populations.

The Charter School was selected because it had outperformed the other two schools on the New York State Assessments. The K-8 public schools was designated a Restructuring Comprehensive School on the 2010-2011 New York State Report Card. Less than half of the fourth grade students met the standards on the ELA exam in 2010-2011. Additionally, the school did not meet their Annual Yearly Progress as determined by the New York State Education Department in English Language Arts. Lastly, the two public schools' New York State Report Cards indicated that their students with disabilities and economically disadvantaged students performed poorly in ELA.

The professional development model meshed both literacy specific content strategies and teacher collaboration through the use of technology. The specific content instruction was in text-based evidence, data analysis to inform instruction, academic vocabulary, making students accountable for their learning, and collaborating/working with a teacher partner on the same grade level, but from different school districts. The technological component allowed teachers to effectively collaborate remotely. This was most effective in facilitating the inter-school grade level teacher partner communication of sharing best practices.

The goals of the dissemination project were as follows:

Goal 1: To be able to use a collaborative coaching model to support research-based literacy practices that will be implemented and assessed in partner classrooms; set up and organize an effective, supportive literacy environment for teaching and learning; and collaborate effectively as part of a professional team. It was to provide teachers with professional development that is aligned with Common Core State Standards. One important skill is close reading, which requires a higher level of understanding complex text. This skill was selected for professional development support due to teachers needing hands-on practical experiences working with the new Common Core demands that raised rigor. We asked teachers to explain what exactly the Common Core Standards mean regarding close reading and how should they teach their students to read closely enough to meet these standards. Close reading stresses engaging with a text of sufficient complexity directly, examining meaning thoroughly, and encouraging students to reread deliberately to find text evidence.

Activities that address goal: Workshops and professional development sessions were provided during the program for staff at the charter school and partner schools. The project director and the site coordinator provided professional development in Dunne \& Villani's [1] collaborative coaching model that links teacher and student learning. The collaborative coaching cycle included: 1) planning conversations, 2) coaching and gathering data, and 3) reflecting conversations.

While establishing staff teams, the authors followed the recommendation set forth by Robinson and Schaible [5], who stated that when establishing collaborative teams, the number of team participants should be restricted to two teachers, as it is too complex to do it well with more. The professional development (PD) team began building upon the working rapport that was guided by the work of Dunne and Villani [1] with the paired partner teams. This PD team was comprised of the project director and the site coordinator, and outside literacy and data consultants when necessary. Specifically, the professional development focused on the following topics: literacy best practices such as interpreting words and phrases, summarizing, determining importance, word and question choice, text based evidence, and academic vocabulary [3].

As part of the program, partner teachers shared literacy strategies in a myriad of ways. These included emails, journal entries, classroom visitations, and reflections focused on selected chapters from the text, Close Reading and Writing from Sources [2]. Also, teachers watched Fisher \& Frey [2] best literacy practice videos and discussed the feasibility of the strategies to be implemented in their own classrooms. Classroom visitations were videotaped implementing the strategies taught during the PD sessions. This use of videotaping allowed both teachers and students to learn these important literacy skills and practices.

During PD session's time was allotted to allow teacher partners to meet and discuss both successes and areas that may require assistance.

As a follow-up to the partner meetings the PD team structured the site visitations to address their literacy classroom challenges.

Goal 2: Structure team/grade meetings that focus on student progress through the use of data; use that 
data effectively to inform instruction (analyze data to determine student needs, chart student progress, make thoughtful programming decisions); and target measureable instructional outcomes with specific student needs in mind.

Activities that address the goal: Workshops and professional development sessions were provided during the program for staff at all three schools. Topics included: analyzing data to determine student needs, charting student progress, and making reflective curricular decisions. These initiatives were selected to specifically address those students with disabilities and of economically disadvantaged backgrounds that were identified in the two public schools' NYS Report Card findings.

Each school developed and administered a mock ELA exam in year 1. Professional development was provided to teach teachers how to effectively analyze the data to determine student needs, chart student progress, and make thoughtful programming decisions. This goal was effectively achieved due to the fact that the data consultant effectively tutored the data managers individually. This was important because each school's data manager had different levels of ability in using data effectively.

Goal 3: Teachers would become reflective in teaching approaches/practices by examining what worked and did not work and determining how to proceed.

Activities that address goal:

- Grade level partner team meetings, both in person and virtually, provided time for teachers to:

- Dialogue and rehearse in-class demonstration lessons and reflect on their teaching approaches as the partners shared literacy best practices, e.g., inference, questioning techniques, effective word choice and academic vocabulary

- Examine what worked and did not work and determine how to proceed

- Initiate partner-teacher dialogue bimonthly to share best literacy practices and other literacy issues

- Initiate videotaping classroom partner teachers' literacy lessons that were shared in PD sessions and reviewed with specific criteria based instruments that delineated the specific strategies that were addressed during previous PD sessions

- Conduct classroom inter-visitations during which teachers observed colleagues from their partner schools. Staff met both before the observations to help observers understand the instructional context and after to debrief. Partners visited each other's schools and observed the teaching of a goal specific lesson, i.e.: text-based evidence, close reading lessons, etc.

- Analyze data from the mock exams to problemsolve and make instructional planning adjustments
- Be guided how to become proficient in error analysis to better inform their instructional decision making

- Review formative assessment data to benchmark entire class and individual student progress

Goal 4: Learn how to make students more accountable for their own learning.

Activities that address goal: The PD team and a data consultant shared different models of effective progress monitoring during the professional development sessions. Additionally, teachers were encouraged to create rubrics based on those models, use them with their students and bring examples to a future PD session. At that follow-up session, teachers shared several models and their students' experiences, which was a productive learning experience for all participants.

In year three, the work continued to achieve the goal of having teachers become more reflective of their literacy teaching practices and further determine the efficacy of their pedagogical expertise. The role of the teachers was expanded so that they could become turnkey personnel in their schools. The site coordinator and project director arranged for times, locations, and other necessary details for videotaping these sessions.

This was accomplished in the following ways:

- Teachers from all three schools were asked to design and conduct a Dissemination Grant goal related literacy lesson or a data analysis meeting/conference for videotaping purposes

- Teachers worked with the site coordinator and project director to select, plan and execute these lessons and or team data meetings

- After the videotaping the site coordinator and project director helped plan and reviewed the lesson with the teacher

- The project director, site coordinator, and the videographer reviewed, edited and added explanatory dialogue and voiceovers to the videotaped lessons to finalize the video

Here are three examples of how the videos demonstrate the goals of the grant: collaboration, data analysis, and effective literacy practices.

- Video 1: The strategy highlighted in this video is how to use data analysis from ELA assessments to inform future instruction. The data meeting observed consisted of an eighth grade ELA teacher sharing his results with the school's data manager. Together they looked at error patterns. They then conducted an error analysis of a mock ELA exam by examining student responses to each question. One may observe them discussing the state indicator for each question as they look for areas that the class may need further instruction as well as individual student intervention. These findings may result in flexible grouping, students needing Academic Intervention Services or peer tutoring. 
- Video 2: The purpose of the data team meeting video was to model the five steps of a data meeting. These steps are those that were implemented as the result of their participation in the professional development conducted during the grant. During the professional development meetings with partner teachers in the other two schools, partners reviewed the data from prior assessments and developed lessons. Then, at follow up meetings participants talked about what worked and what did not work with their students.

As a result of working with the SPLASH grant in years one and two, interdisciplinary relationships were formed that strengthened the instruction with teacher partners.

The data team model is what was highlighted in our professional development SPLASH meetings and now is an adopted practice at the Middle School. The steps are as follows:

Step 1 is to review the class and grade level data. In this step teacher's look at the number of students taking the assessments, look at the percentages of students that are proficient or at a higher level, look at the percentages of students who are not proficient, and then analyze work samples to find further evidence to diagnose patterns of errors.

Step 2 is analyzing the obstacles and identifying areas that can be remediated. Beginning with asking questions that would answer why the student is having difficulty and what strategies should be planned to help the individual student.

Step 3 is establishing and reviewing SMART goals. SMART goals are Specific, Measurable, Attainable, Relevant, and Timely.

Step 4 is to determine instructional strategies. Look at what specific strategies are going to be used in different English/ ELA classrooms. The Middle School has an English class, an English lab class, and a Read 180 class. It is important that the instructional strategies of all three classes be aligned to meet specific student needs.

The video demonstrates how collaboration and data analysis is an effective tool for teachers to work together to improve literacy instruction. At the conclusion of the video teachers agreed to meet again to not only look at the two assessments, but also to start to talk about how they can use this information to look for improvement and areas that still need targeted instruction.

- Video 3: This video was a lesson that demonstrated how to help students identify relevant evidence by paying close attention to the text features and structure of nonfiction text.

First, the teacher posed the following question to the class "what are the ways in which readers notice important evidence in nonfiction text?" The teacher shared with his class some of the ways to look at the text to find this information: a) Subheadings

b) Structures - sequence, cause \& effect, compare and contrast, problem and solution, and description Next, the teacher modeled by reading aloud a nonfictional article. After the reading, he asks the class, "Explain how the quote from paragraph 3 contributes to the article." This question demonstrates the students' ability to think of the main idea of the text so far and apply that knowledge to explain how the detail contributes to the central idea of the text.

Then, students independently read the nonfiction article again. After finishing, students were asked to complete the questions following each passage. During that time, the teacher individually conferenced and monitored student responses while encouraging students to collaborate on the questions.

In closure, the teacher explained how using subheadings helped students in locating relevant evidence; using the main idea helped in locating relevant evidence and how understanding text structure helped students find relevant evidence.

The teacher debriefed after the video and shared his enthusiasm about the lesson and his new confidence. Prior to this in year 1 and 2 he was reluctant to have visitors to his class or teach before an audience. It is believed that this excellent teacher now realizes that collaborating with other teachers not only improves student instruction, but has made him a more reflective teacher.

\section{Discussion}

The New York State Education Department hired an external evaluator to determine the success of the Dissemination Grant programs. When citing significant progress, the external evaluator reported that when SPLASH participants were asked about the extent to which participating in the Charter School Dissemination Grant had affected their skills as an educator in a number of diverse areas the respondents stated that they recognized improvements, particularly in their abilities to function as a member of a professional learning community after Year 1. The effect was even greater at the end of Year 2, where the biggest difference was seen in participants' abilities to function as part of a data culture and literacy strategy acquisition. Teachers involved in the dissemination grant learned that strategies best after they observed a colleague implementing that strategy with their students. Afterwards, they attempted teaching the strategy with a similar lesson in their classroom. Following those experiences, teachers were provided the opportunity to debrief with the observed teacher utilizing the authors created Classroom Observation Checklist. The checklist asked teachers to respond to the following queries and provided a basis for the debriefing sessions:

how did the teacher: 
- $\quad$ set the purpose of the lesson

- help students make connections to prior learning

- use a specific strategy to encourage students and help keep focus

- help facilitate learning of text based evidence

- $\quad$ assess student learning

This authentic lesson and observation resulted in a better understanding of the strategy- its usefulness and the pedagogical pattern that is needed so that the teachers would be better able to teach it effectively, not only to their own students, but also to their colleagues. This was evidenced by the following qualitative responses on 12 evaluation surveys:

- I enjoyed additional interactions with other teachers

- Collaborating with teachers and sharing resources

- Collaboration on analysis templates and mock exams

- Standardizing the data collection

- There was a presented skill that addressed the "checklist" of things to consider while answering test questions.

I will be implementing a similar strategy in my classroom for the coming month.

Furthermore, teachers responded that the data from the ELA benchmark assessments allowed them to create specific skill-oriented lessons for small group instruction.

Additionally, the staff provided some examples of how the SPLASH program had affected their schools. Below are direct quotes from the surveys:

- The grant brought the English, Social Studies and Reading department together as a collaborative team.

- I think it has made us more aware of our practices. Since we want to appear as a mentor school, we are more conscious of our instructional and databased decisions.

- We are more data focused now, working collaboratively and spreading the new practices into other subjects. Another set of evaluative questions asked SPLASH participants to give examples of how they were doing things differently as a result of applying the literacy strategies:

- I have helped students to use close reading strategies.

- I rearranged my lessons to include stronger academic vocabulary activities. Some educators are using the literacy strategies outside their regular classroom setting:

- Incorporating more close reading strategies.

- I have shared strategies with other teachers, and students who are not in my classroom with the hopes of providing understanding.

- It has helped me to become a better researcher.

\section{Conclusion}

The findings suggest that this professional development model was successful due to a three prong specifically targeted approach: collaborative coaching, targeted literacy strategies/ classroom practices, and interschool classroom visitations. Danielson [6] stated:

"Schools should not rely on evaluation as their main engine of teaching improvement,...]'s time to shift from an emphasis on high-stakes accountability for individual teachers to an emphasis on school-wide communities of professional inquiry in which educators learn from one another."

This was evidenced in the professional development evaluation surveys conducted by the external evaluator, which support the findings and confirm future replication of this project. The results of the study were overwhelmingly positive and strongly suggest that this is a model that should be replicated in both public and private schools that want to ensure teacher quality and maximize student achievement. This professional development demonstrates promise for supporting meaningful shifts in practice. No longer is the out of town expert professional development model working. There needs to be more of a focus and interface of shared inquiry in a learning community where there is a collaborative spirit created and sustained by professionals over a period of time. In this program, participating teachers reflected on practices and made important instructional shifts.

\section{References}

[1] Dunne, K. \& Villani, S., (2007). Mentoring New Teachers through Collaborative Coaching: Facilitation and Training Guide. WestEd: San Francisco, CA, 2007.

[2] Fisher, D. \& Frey, N., (2014). Close Reading and Writing from Sources. International Reading Association: Newark, DE.

[3] Marzano, R.J., (2009). Teaching Basic and Advanced Vocabulary: A framework for direct instruction. Heinle and ASCD: Alexandria, VA.

[4] National Governors Association Center for Best Practices and Council of Chief State School Officers (2010). Common Core State Standards for English Language arts and literacy in history/social studies, science, and technical subjects. Washington D.C.: authors.

[5] Robinson, B. \& Schaible, R.M., (1995). Collaborative teaching: Reaping the benefits. College Teaching: Vol. 43, No. 2, pp.57-59. Taylor and Francis, Ltd.: Milton Park, England. 
[6] Danielson, C., (2016). Best Ways to Improve teaching "Creating Communities of Practice Educational Leadership, May 2016 (Vol.73, \#8.pp.18-23).

[7] Thiers, N., (2016). Educators Deserve Better: A Conversation with Richard DuFour. Educational Leadership, May 2016 (Vol. 73, \#8, p. 10-16). 